\section{Concert and Festival Reviews}

\section{The GRM in New York City November 14, 2008 Chelsea Arts Museum} by Sam Pluta

Having lived in New York City for over two years, it would be hard to convince me that any other place has such a diverse wealth of music to choose from every night of the week. From experimental electronic to instrumental, from the Met to Broadway, and from Country to Cajun, everything can be found in this city if you look hard enough. However, if there is one form of music that is significantly underrepresented here, it is multi-channel acousmatic music. There are reasons for this; not only do most institutions lack the required equipment, but suitable venues are in short supply. Most are small and narrow, not allowing for a wide spacing of the side speakers that allows the multichannel setup to work. This is why I was so thrilled that the Electronic Music Foundation was bringing Daniel Teruggi, Marc Battier, and François Bayle to the Chelsea Art Museum to showcase their music. These three gentlemen are members of France's oldest electronic music studio, the Groupe de Recherches Musicales. The organization's fifty-year history has had a dramatic impact not only on electronic music, but also on music in general, and to hear their multichannel sounds in New York would be a bit of a treat.

The concert was held on the third floor of the museum. The space was sufficiently large and the EMF's sound system, while no BEAST, was acceptable, consisting of 8 speakers in a circle around the audience plus a necessary subwoofer. On the down side, the venue shared a feature with so many wonderful New York venues - road noise. The Chelsea Art Museum borders the West Side Highway, and while we have become accustomed to car horns in our Cage and sirens in our Feldman, a music whose main foci are audiophile sound quality and pristine effects gets somewhat lost in all the noise (a side note - this actually makes so much more sense out of Cage, but is perplexing in the case of Feldman).

On to the music. Daniel Teruggi, the current director of the GRM (though a native Argentinian), started out the concert by presenting his 2006 multichannel work, Birds. The piece was sparse in gesture, but aesthetically and technically gorgeous. The entire twentyminute or so piece had probably five gestures throughout, yet these were somehow kept fresh with unique pacing and focused augmentation. Mr. Teruggi's piece portrayed a remarkable sense of space, with sounds appearing as close 
as the nearest speaker, as far away as possible, and everywhere in between. In conjunction with this, Birds also contained the softest gestures in the concert, which forced the listener to engage with his music as it was swallowed by highway traffic (I rather enjoyed this, though my conversation with the composer after the concert led me to believe he did not). Though suffering from perhaps one too many false endings, Birds was an engagingly beautiful work with clear highs and powerful lows, and one that I was glad to hear in all its multi-channel glory.

Marc Battier's Capital Bird (no relation to the previous work) was the only piece to feature an instrument, in this case the Japanese shakuhachi flute. Mr. Battier was able to create some very fine granular textures out of a ninth-century Japanese poem, written by Ariwara no Narihira and read by Franck Royon Le Mée. These fit well with the shakuhachi's airy, noisy sound, and overall the piece had a pleasant arch to it.

François Bayle was certainly the drawing

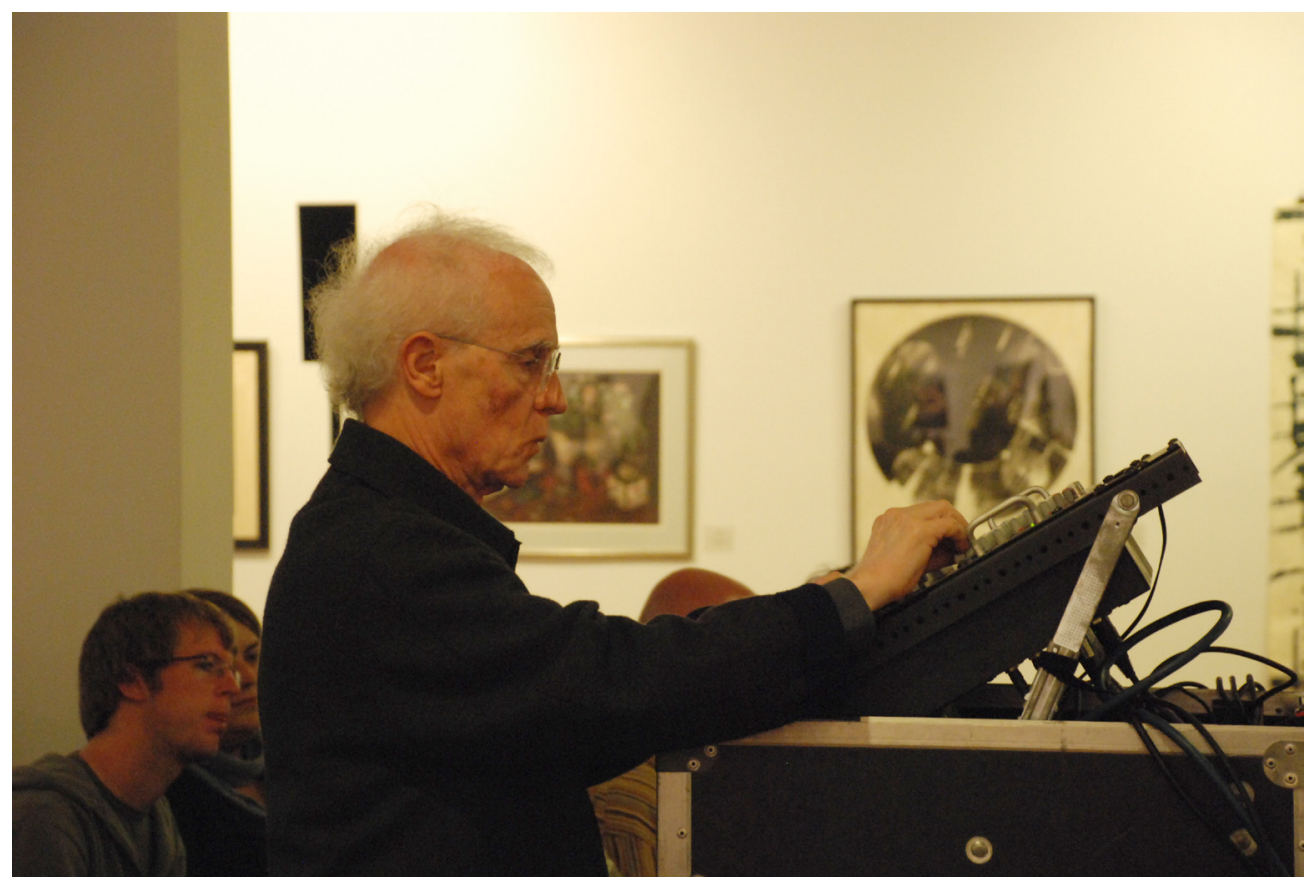

François Bayle performs at the Chelsea Art Museum, November 14, 2008. Photo by Amy Eisinger. 
point for the evening. As director of the GRM for over 25 years, and composer before and since, Bayle is a major figure in acousmatic music: so much so that he is the one to have coined the term. In the pre-concert talk, Dr. Bayle (honorary from University of Cologne in 2005) discussed his current work as an exploration of microworlds, an exploration of tiny sounds that can be exploded into larger forms. This became clear when Univers nerveux, in memoriam Karlheinz Stockhausen was played. This music was alive with detail. Bayle took the maximalist approach, directly the opposite of Teruggi's work, inundating the listener with a constantly changing collage of swoops, swirls, clouds, and drones. The sounds were beautifully engineered, but at the same time strikingly organic. Similar to Dhomont and Parmeggiani, Bayle seems able to construct an electronic gesture that is fully artificial, yet with a visceral quality reminiscent of physical action. Why only these pioneers of tape music seem able pull this off, I don't know, but like many electronic composers to follow these gentlemen, I would love to know their secret.

After the concert, I spoke with the three composers, and learned that François Bayle has just released a new book on the correlation of hearing and seeing, Diabolus in Musica, with text in French and English. I look forward to reading it.
I am also looking forward to the spring of 2010, when the HiFi festival brings Jonty Harrison to town for a concert featuring his music. However, while I find the prospects of an acousmatic scene in New York exciting, I wouldn't want it to take over as it has in much of the country. There are too many good things going on here in the realms of improvisation, installation, robotics, and experimentation. But if a city truly never sleeps, there should be time in the day for all kinds of music, and hopefully multichannel tape music can be one of them.

Sam Pluta is a composer and improviser living in New Tork City.

\section{NYGEMF Review April 2-4, 2009 Eileen Mack}

After the miserable grayness of one of New York's April showers, it was a relief to step into the warm darkness of CUNY's Elebash Theater, if only to catch the last work of the afternoon's program. It was refreshing to hear an electronic piece, in this case Thomas Dempster's contact clusters, presented in such an acoustically resonant space. Samples of pizzicato and arco strings, used both on their own and processed, had such body that it seemed as if there might be a lone performer hiding in the blackness on stage. I returned the next day for a 
session in the Segal Theater, a space that was somewhat less conducive to depth of sound.

Emmanuelle Weckerle's $A$ duet (virtually) stood out from everything else on the program. It was the only interactive work I saw presented in concert, and it featured the composer on stage dressed to match her recorded image, projected on video. Her offstage colleague, Sebastian Lexer, interacted with the video by moving a cursor around the avatar's body parts, eliciting various gestures and vocal sounds. An interesting concept, this iteration of Weckerle's VINST project was disappointing and at times uncomfortable to watch. The graphics were somewhat low quality, the palette of sounds limited, and I was puzzled as to the nature of the interaction between the onscreen and live performer. The path of the cursor was predictable, starting at the head and heading inevitably down to a silver ball hanging from the nether regions of Weckerle's costume. The spectacle of virtual and live woman being manipulated by a shadowy male figure suggested philosophical questions beyond the ideas of Deleuze mentioned in the program note.

In contrast to this improvisational and puzzling duet, Mark Zanter's $s 2$ began in a harmonically coherent vein, making thematic use of simple chords and a sonic palette of organ- and bell-like synth sounds. It flirted occasionally with the line between electro-acoustic composition and new-age background music, fading out at the end into the roar of a passing subway train. Jay Batzner's Carnival DaringDo, with accompanying film, replaced nebulousness with clear and detailed, if fantastic, imagery. The film was an animated, grayscale mixture of cinema pre-reel characters and optical floaters, trilobites and candy canes cavorting over monotonous plains. The soundtrack used appropriately skittish and smallscale sounds: chimes, woodblocks, and mysterious scrabbling.

Shatter, by Marc Aigner, opened with crescendoing blocks of various apocalyptic sounds, including breaking glass, industrial machinery, jackhammers and car crashes. What at first seemed like a series of stock action movie sound effects revealed itself to be a very clever juxtaposition of sounds exploring similarities and contrasts with often witty effect, as in a sequence including tinkling champagne glasses, gravel, and the sound of cereal in a bowl. This succession gradually morphed into more regular sounds like clapping, knocking and ticking. The piece wound down into an ambient wash complete with rushing water and chirping bird sounds - a quirky ending to such a collection of man-made sounds. 
All the sounds used in Konstantinos Karathanasis' De Ligno Chalybeque were generated from cello samples, yielding a warm sonic palette suggesting wood drums, bells and flute as well as more obvious string sounds. A gentle beginning, with underlying synth, hum and air sounds, gave way to a more ominous and uneasy segment. Overall, this created an especially effective sound world, which was unfortunately punctured by a painfully swift raising of the lights at the end of the session.

The scheduled first work on the next program, Vera Ivanova's Escape for piano and electronics, was replaced by another piece by the composer for electronics alone entitled Panic. Melancholy. The dichotomy in the title was represented sonically in alternations between episodes of hectic cacophony and reiterations of a single pure tone. Later in the piece, processed vocals start to infiltrate these absolute concepts - shrieks, choral fragments, and sounds of angry crowds. An underlying interference-like pulse infused the whole work. Ms. Ivanova ran the board, perhaps a little overenthusiastically, as there were several drawn out high frequencies that had even this audience (presumably accustomed to aural challenges) plugging their ears.

Arthur Gottschalk's Contrary Variants hearkened back to an earlier, Davidovsky- esque sound palette. The addition of a live performer (the excellent Jane Rigler, on flute) illustrated a recurring problem: that of aural position and balance between the single acoustic sound source and multiple speakers. Apart from this, the piece was well crafted and assured, though rather short, with clever interplay between the flute and tape. Pianist Juraj Kojs took the stage next and prepared for Jason Bolte's Scrap Metal by weighting down the sustain pedal and donning headphones. Here the piano timbres, including tapping and playing inside the piano, balanced well with the resonant metallic sounds of the electronics. The result was an adventurous exploration of timbral variation, with the piano only occasionally overwhelmed by the tape.

The appearance of a lone bassoonist on stage seemed potentially quixotic, but Peter Van Zandt Lane proved to be the hero of the program, eliciting whistles and a shouted "yeah!" from the audience by the end of his piece, Aeromancer. Running his own setup (laptop and interface) from the stage, Van Zandt Lane began with an angular atonal bassoon solo, soon joined by high open chords and burbles in the electronics. Some interesting pitch interactions between instrument and tape, and later a delay effect on certain pitches in the bassoon part, had me wondering how the electronics were tracking the live part - a question partially solved when 
the soloist stood to take a bow, revealing a MIDI pedal at his feet. The piece ended satisfyingly with a fade back into sounds from the beginning, accompanied by sonorous romantic harmonies. This piece too suffered occasionally from timbral blend problems, which might have been solved with a little amplification of the bassoon.

Jean Ahn's slight piece Berkeley Arirang, apparently based on a Korean folk tune, again featured piano synced to the electronics via click-track. The tape seemed excessively soft, coming across as a processed echo or shadow of the instrumental part, which made interesting use of glissandi. It looked like violinist Spencer Topel began the following work, David A. Jaffe's Impossible Animals, before the engineer was quite ready, but an impressive scramble to open sound files and start the electronics seemingly saved the day. The piece mixed elegant melodies in the violin with synthesized vocal syllables. The violin often followed the pitch contours of the tape part, contrasting the beauty of the acoustic instrument with the slight awkwardness of the electronic voice. However, the climax of the piece turned the tables, presenting a rather astonishing and very impressive section in which a synthesized human voice followed the exact contours of the song of a wren.
Joshua Clausen's work saw the return of a be-headphoned Juraj Kojs, and though titled she quietly enters and leaves the fray, it began with some unfortunate click bleedthrough. The hip-hop beats of the tape part contrasted weirdly with the unamplified piano sound, while their rhythmic sophistication sat uneasily with the harmonically simple and rhythmically square piano riffs. The piece was more successful when the piano was used for a more chordal or minimalist texture. An already long concert was extended when composer-violinist Mark Zaki encountered difficulties with his setup in the final piece, On Reflection. The characteristic Apple reboot chord gleaned knowing and sympathetic chuckles from the audience. This piece used looping and delay to layer sumptuous violin laments to beautiful effect, although Zaki's demeanor suggested that things weren't quite as they were meant to be.

The last session I attended began with Monty Adkins introducing and lauding the facilities at the University of Huddersfield where he is on faculty, including a new 25-speaker venue. The pieces on this program occasionally erred on the side of exulting technical ability and innovation over compositional interest. Adkins' two works on the program, Five Panels no. 1 and 5, certainly showed a masterful use of the surround system. He used the full dynamic range 
of the speakers, including sounds on the edge of audibility (an extreme of dynamic neglected in most other works). His soundscapes were smoothly and subtly blended and integrated, perhaps in reflection of the Rothko paintings that inspired this suite of works. The palette, including marimba, pizzicato and water drops over an ambient bed, held my interest throughout the first Panel, despite sometimes getting rather close to an Enyalike new-age sound. Panel no. 5 ended the program, and was accompanied by video by Pamela Harling featuring shots of cracked mud and granular, lensed images. The video helped to delineate structure in what could otherwise have come off as an amorphous piece.

Pierre Alexandre Tremblay also had two works on the program, Walk That Way. Tuesday, Turn and la cloche fêlée. Tuesday featured accompanying video in a similar style to the Adkins, although no artist was credited. True to his fatalistic program note ("Inhale. Exhale. Repeat until life ceases"), Tremblay evoked mortality with the use of inescapable repetitive sounds, often in polyrhythms - ticking, shakers, Geiger counters. The video synced perfectly to the music in several rhythmic sections, and featured fitting visuals suggesting fleeting schools of fish, ominous silhouettes, explosions, and finally what could have been a blurred human face. The end of the piece saw the intrusion of birdsong, alluding perhaps to the inescapability of Nature? La cloche fêlée was similarly philosophical. Based on a poem by Baudelaire (in English, The Broken Clock), it used more ticking as well as a climactic tree fall and tolling bell to evoke its inspiration's darkness. Michael Clarke's Tim(br)e II rounded out the program. All of the sounds in this work were derived from an oboe sample, which peeked out in its original form at the end, after a long crescendo and final flourish. GUNY and the Festival organizers are to be congratulated; the music presented showed a wide range of current activity in the field, and the sound technicians and stage crew were consistently excellent. 